\title{
Exchange rate regimes and asset prices *
}

\author{
Harris Dellas ${ }^{\dagger} \quad$ George Tavlas ${ }^{\ddagger}$
}

October 12,2012

\begin{abstract}
We study the implications of alternative exchange rate regimes for asset prices in a portfolio balance model motivated by the recent US-China experience. We establish that asset price responses to various shocks differ across a flexible regime and a -unilateral- peg but the differences for most shocks tend to be rather small. Moreover, while both monetary and public debt expansions have inflationary effects on equity prices, the latter's impact is stronger under a flexible exchange rate regime. These two findings suggest that a flexible USD/rimni rate would not have limited the recent asset price inflation in the US.
\end{abstract}

JEL class: E4

Keywords: Asset price inflation, exchange rate regime, portfolio balance, US-China.

\footnotetext{
*We would like to thank Marios Angeletos, Pierpaolo Benigno and Behzad Diba for useful comments.

${ }^{\dagger}$ Department of Economics, University of Bern, CEPR. VWI, Schanzeneckstrasse 1, CH-3012 Bern, Switzerland. Phone: +41 (0) 31-631-3989, harris.dellas@vwi.unibe.ch, www.harrisdellas.net

${ }^{\ddagger}$ Bank of Greece, GTavlas@bankofgreece.gr.
} 


\section{Introduction}

Does the current international monetary regime encourage asset price inflation? During the last decade, the prices of many assets, including stocks, bonds and real estate, experienced significant, sustained upward movement in the USA (and also in other industrial countries). Even after a temporary retreat during the financial crisis, asset prices have continued (with the exception of real estate) their climb. At the same time, real long term interest rates have been quite low. And the US has run very large current account deficits, in particular vis a vis the East Asian countries, and this has been accompanied by massive foreign (USD) reserve accumulation by the central banks in those countries. Are these phenomena linked? And do they have anything to do with the prevailing international monetary arrangements?

Several papers have attempted to account for the nexus of large capital flows from developing countries into US safe assets (government bonds), persistently low US long term real interest rates and large US current account deficits. For instance, Caballero et al., 2008, have argued that fast growth in countries with underdeveloped financial systems (countries that cannot supply "good" financial assets to their residents) led to increased global demand for the "high quality" assets of the developed countries. Caballero and Krishnamurthy, 2009, trace out the implications of these flows for asset prices and rates of return on safe and risky assets in the US and also discuss their potential contribution to the financial crisis. Similarly, Dooley et al., 2004, have argued that the placement of a large share of the savings of emerging markets in US safe assets depressed real interest rates in the US and altered relative yields of risky and safe assets.

In Dooley et al., the decision of LDC governments to place much of domestic savings in US safe assets is closely related to their choice of the exchange rate regime, and in particular, to what has come to be called Bretton Woods II (BWII). BW II involves the pegging of the Chinese currency (as well as those of other East Asian countries) to the US dollar. The peg has been motivated by China's export-led growth, excess-labor absorption strategy. It has been supported by China's foreign reserves policy in conjunction with capital controls on private capital outflows. And it has led to the accommodation of large US current account deficits through the accumulation of vast, liquid, foreign reserves by the Central Bank of China. For instance, the change in China's official foreign reserves in 2007 was more than $50 \%$ of the US current account for that period (258bn and 450bn respectively). Most of the official reserves are in US government or GSE bonds. China's desire to finance US current account deficits at -relatively- stable terms of trade by holding safe, liquid, dollar denominated assets seems to have been a key driving force behind the decline in long term real interest rates in the US during that period notwithstanding the large increase in the supply of such assets that occurred through 
loose monetary policy and government budget deficits.

The implications of the decline in real interest rates for private portfolios and asset prices are straightforward. Facing a lower riskless rate of return, US and international investors change the composition of their portfolios in favor of riskier assets (stocks, real estate), pushing their prices up. As long as the forces outlined in the basic scenario above (fast growth in China, stabilization of the US-Chinese terms of trade) remain active, the upward pressure on asset prices remains.

How does the exchange rate regime matter in this scenario? There are two elements of relevance here, one general and the other specific. The general element concerns the fact that -at least over the short run when nominal goods prices are sticky- a peg means that the terms of trade cannot move much. For some shocks, this may imply that foreign account imbalances cannot be mitigated by countervailing terms of trade adjustments, contributing to larger US deficits, larger foreign reserve accumulation in China and a larger effect on US real interest rates than what would have occurred if the terms of trade could adjust (under a flexible exchange rate system). The specific element is that the peg is accompanied by controls on the outflow of capital as well as by limited wage adjustment in China. The latter implies that exchange rate policy also matters for the terms of trade over the medium term. And the former supports the bias of Chinese portfolios in favor of low risk, liquid USD assets.

Our view is that the increase in the demand for US safe assets may have multiple sources. But whatever the sources, the fact that China has been managing is exchange rate and that it has accumulated vast, safe, liquid USD assets (reserves) in this process (a large fraction of the US CA deficits) cannot be ignored in the analysis of the determination of asset prices in the US. A flexible exchange rate regime might have conceivably implied quite different paths of the Chinese terms of trade, current account surpluses and international portfolios. It is thus of interest to know whether asset prices behave differently under alternative exchange rate systems. In particular, whether fixed regimes may encourage higher price inflation than flexible regimes and for what types of shocks.

The objective of this paper is address this question. We employ a simple, flexible price, portfolio balance model, with bonds and equity and compare the effects of various shocks on asset and goods prices across a unilateral peg and a flexible exchange rate regime. We find that the two shocks that have figured prominently in recent studies (an increase in the effective labor supply in China and an increase in the appetite of LDCs for US safe assets) do deliver a decrease in US real interest rates and an increase in asset prices. Nonetheless, the differential impact across exchange rate regimes for these two shocks is quite limited. We also find that monetary and public debt expansion in the US can exert a powerful and persistent effect on equity prices in the US, even under flexible prices. Interestingly, the latter's effect is considerably 
more pronounced under a flexible exchange rate regime. These findings suggest that the pegging of the USD/rimnii rate may not have made a difference for asset price inflation in the US, which supports the view ${ }^{1}$ of Caballero et al., 2008.

\section{The model}

The basic structure follows Dellas (2006). world consists of two countries, "home" (the US) and "foreign" (China). The structure of production and trade are quite standard. In each country, monopolistically competitive firms employ domestic labor to produce intermediate goods which can be either used domestically or exported to the other country. Home and foreign intermediate goods are combined to produce a perishable final good that is consumed domestically.

The residents of the home country save by either trading a one period, safe, nominal bond denominated in the home country's currency and issued by the home country's government, or by holding the equity of the home and foreign intermediate goods firms. The residents of the foreign country face more limited portfolio choice and can only save by trading the home currency bond ${ }^{2}$. This portfolio structure is meant to capture the observed asymmetry in the portfolios held by the two countries. Under a unilateral peg by the foreign country, also that country's government is assumed to hold the home currency bond, and adjust its holding in order to maintain a fixed nominal exchange rate parity.

We now offer a more detailed, formal description of the model.

\subsection{Home country}

\section{Households}

In period 0 the representative agent in the home country maximizes expected lifetime utility

$$
E_{0} \sum_{t=0}^{\infty} \beta^{t} U\left(C_{H t}, h_{H t}, B_{H t} / P_{t}\right)
$$

subject to the sequence of budget constraints

$$
\begin{array}{r}
P_{t} C_{H t}+B_{H t}+S_{H t} Q_{H t}+S_{F t} Q_{F t}+T_{H t}= \\
W_{H t} h_{H t}+\left(1+R_{t-1}\right) B_{H t-1}+S_{H t-1}\left(Q_{H t}+\Delta_{H t}\right)+S_{F t-1}\left(Q_{F t}+e_{t} \Delta_{F t}\right)
\end{array}
$$

\footnotetext{
${ }^{1}$ Caballero et al., speculate that the exchange rate regime has been unimportant. Nonetheless, there is nothing in their analysis or in the extant literature that supports this view.

${ }^{2}$ Alternative asset portfolios, for instance, allowing also the foreign residents to hold equity or allowing private agents to issue private bonds, can be easily accommodated. See Collard et al., 2007, for how to solve for optimal international portfolios.
} 
where $\left\{C_{H t}, h_{H t}, B_{H t}, S_{H t}, S_{F t}, \Delta_{H t}, \Delta_{F t}\right\}$ are home consumption, labor, bond holdings, holdings of domestic equity, holdings of foreign equity, dividends on home firms equity and dividends on foreign firms equity respectively. $\left\{P_{t}, Q_{H t}, Q_{F t}, W_{t}, R_{t}, e_{t}\right\}$ are the home country $\mathrm{CPI}$, the -nominal- price of one unit of home country equity, the nominal price in terms of the home currency of one unit of foreign equity, the nominal home wage, the nominal interest rate and the exchange rate (units of home currency per one unit of foreign currency) respectively. $T$ is a lump sup tax (transfer). $E_{0}$ denotes conditional expectation at date zero.

Dividends are given by

$$
\begin{array}{r}
\Delta_{H t}=P_{H t} X_{H t}-W_{H t} h_{H t} \\
\Delta_{F t}=P_{F t} X_{F t}-W_{F t} h_{F t}
\end{array}
$$

where $X_{H t}$ and $X_{F t}$ are the bundles of home and foreign intermediate goods and $P_{H t}$ and $P_{F t}$ are the corresponding nominal - in terms of own currency- price indexes. Note that labor is the only factor of production.

Including bonds in the utility function is the simplest (and quite innocuous from the perspective of the objective of this paper) way to support a meaningful portfolio choice in the model. In addition to its simplicity, it also helps capture the special international liquidity value of US Treasury bonds. Using an alternative approach to compute time varying portfolios (for instance, see Devereux and Sutherland, 2010) is feasible but does not add much to the analysis for the issues addressed in this paper.

We will assume that the utility function takes the form

$$
U\left(C_{H t}, h_{H t}, B_{H t} / P_{t}\right)=\frac{C_{H t}^{1-\sigma}}{1-\sigma}-\nu_{H t} \frac{h_{H t}^{1+\phi}}{1+\phi}+\psi_{H t} \frac{\left(B_{H t} / P_{t}\right)^{1-\gamma}}{1-\gamma}
$$

where $\nu$ and $\psi$ are shocks whose properties are defined below. Letting $\Lambda_{H t}$ be the Langrange multiplier associated with the budget constraint, the first order conditions with regard to $\left\{C_{H t}, h_{H t}, B_{H t}, S_{H t}, S_{F t}\right\}$ are: 


$$
\begin{array}{r}
C_{H t}^{-\sigma}=\Lambda_{H t} P_{t} \\
\nu_{H t} h_{H t}^{\phi}=\Lambda_{H t} W_{H t} \\
\frac{\psi_{H t}}{P_{t}}\left(\frac{B_{H t}}{P_{t}}\right)^{-\gamma}-\Lambda_{H t}+\beta E_{t} \Lambda_{H t+1}\left(1+R_{t}\right)=0 \\
\Lambda_{H t} Q_{H t}=\beta E_{t} \Lambda_{H t+1}\left(Q_{H t+1}+\Delta_{H t+1}\right) \\
\Lambda_{H t} Q_{F t}=\beta E_{t} \Lambda_{F t+1}\left(Q_{F t+1}+e_{t+1} \Delta_{H t+1}\right)
\end{array}
$$

\section{Intermediate goods firms}

Monopolistically competitive, intermediate firm $i$ uses homogeneous labor to produce an intermediate good $X_{H i}$. The good is produced according to the linear technology

$$
X_{H i t}=A_{H t} h_{h i t}
$$

where $A_{H}$ is an aggregate technology shock and $h_{H i t}$ the amount of labor employed by firm $i$. In this section we assume that prices are flexible so that we can highlight the role of portfolio balance considerations. In the appendix we repeat the analysis assuming price stickiness. Profit maximization $\Pi_{H i t}=P_{H i t} X_{H i t}-W_{H t} h_{H i t}$ leads to the optimal price

$$
P_{H i t}=\mu \frac{W_{H t}}{A_{H t}}
$$

$\mu$ is the markup (defined below).

\section{Final goods firms}

Final goods firms are perfectly competitive. They select bundles of home and foreign intermediate goods, $X_{H H t}=\left(\int_{0}^{1} X_{H i t}^{\frac{\theta-1}{\theta}} \mathrm{d} i\right)^{\frac{\theta}{\theta-1}}$ and $X_{H F t}=\left(\int_{0}^{1} X_{F i t}^{\frac{\theta-1}{\theta}} \mathrm{d} i\right)^{\frac{\theta}{\theta-1}}$, where $\theta \in(0, \infty)$, in order to produce a final good, $Y_{H t}$, according to the production function

$$
Y_{H t}=\left[\omega_{H}^{1 / \eta} X_{H H}^{(\eta-1) / \eta}+\left(1-\omega_{H}\right)^{1 / \eta} X_{H F}^{(\eta-1) / \eta}\right]^{\eta /(\eta-1)}
$$

with $\eta \in(1, \infty)$ and $\omega_{H}$ is the share of home intermediate goods in the production of the home final good. The maximization problem leads to the input demand equations 


$$
\begin{array}{r}
X_{H H t}=\omega_{H}\left(\frac{P_{H t}}{P_{t}}\right)^{-\eta} Y_{H t} \\
X_{H F t}=\left(1-\omega_{H}\right)\left(\frac{e_{t} P_{F t}}{P_{t}}\right)^{-\eta} Y_{H t}
\end{array}
$$

The prices $P, P_{H}, P_{F}$ are the standard price indexes $P=P\left(P_{H}, e, P_{F}\right), P_{H}=P_{H}\left(P_{H i}\right), P_{F}=$ $P_{F}\left(P_{F i}\right)$. Note that goods sold abroad are denominated in the producers' currency, that the mark up, $\mu$, is simply equal to $\theta /(\theta-1)$, and that home consumption, $C_{H}$, is equal to home final good production, $Y_{H}$.

\subsection{The foreign country}

The behavior of the foreign country agents is completely analogous to that of the domestic agents. The only differences pertain to the fact that they do not hold any equity. It should be mentioned at this point that we will use the leisure preference shock, $\nu_{F t}$, to capture variation in the supply of labor in China. While this shock cannot do full service to the idea that there is a vast pool of under-employed workers in that country that is being absorbed by the fast expanding non-farm sectors without any major effects on the real wages (other than those arising from higher productivity), it can help generate the combination of higher employment with unchanged wages for various shocks.

\subsection{Additional elements}

Let $B_{t}$ be the supply of home currency bonds issued by the home government, $B_{F} 0$ their quantity held by foreign residents and $B_{F}^{G}$ the quantity held by the foreign government $\left(B_{F} \geq 0, B_{F}^{G} \geq 0\right)$. The current account, $C A_{H}$, of the home country is then given by

$$
\begin{array}{r}
C A_{H t}=-\left[\left(B_{F t}+B_{F}^{G}\right)-\left(B_{F t-1}+B_{F t-1}^{G}\right)\right]= \\
P_{H t} X_{F H t}-e_{t} P_{F t} X_{H F t}-R_{t}\left(B_{F t}+B_{F t}^{G}\right)+e_{t}\left(P_{F t} Y_{F t}-W_{F t} h_{F t}\right) S_{H F t}
\end{array}
$$

where $X_{k j}$ denotes sales in country k of the intermediate good produced in country $\mathrm{j}, k, j=H, F$.

The budget constraints faced by the two governments are

$$
\begin{aligned}
& B_{t}+M_{H t}+T_{H t}=\left(1+R_{t-1}\right) B_{t-1}+M_{H t-1} \\
& B_{F t}^{G}+M_{F t-1}=T_{F t}+\left(1+R_{t-1}\right) B_{F t}^{G}+M_{F t}
\end{aligned}
$$


where $T$ is a lump sum tax (transfer) and $M_{H}$ and $M_{F}$ are the domestic and foreign supply of money respectively.

To complete the nominal side of the model we postulate simple money demand equations

$$
\begin{aligned}
& M_{H t} v=P_{t} C_{H t} \\
& M_{F t} v=P_{t}^{\star} C_{F t}
\end{aligned}
$$

where $C_{F}$ is foreign consumption, $P^{\star}$ is the foreign CPI and $v$ is a velocity variable.

Finally, we have the market clearing conditions

$$
X_{H}=X_{H H}+X_{F H}, X_{F}=X_{F F}+X_{H F}, S_{H H}=1, S_{H F}=1, B_{t}=B_{H}+B_{F}+B_{F}^{G}
$$

We consider two alternative exchange rate systems. A unilateral peg, under which the foreign government adjusts the holdings of its foreign reserves (home currency bonds) in order to insulate the exchange rate from the effects of shocks. And a flexible exchange rate regime. Under either regime, the money supplies in the two countries are assumed to be exogenous.

\section{Calibration}

For simplicity, we assume that the current account is zero in the steady state, that is,

$$
R_{t}\left(B-B_{H}\right)=e\left(P_{F} Y_{F}-W_{F} h_{F}\right)
$$

We select the value of foreign official reserves $B_{F}^{G}=B-B_{H}-B_{F}$ so that this condition is satisfied.

Table 1 reports the parameter values used in the analysis. It should be kept in mind that the model is not designed to serve as a vehicle for serious quantitative analysis but rather to be suggestive of the effects of various shocks on asset prices.

There are several shocks in the model. In particular, there are shocks to: domestic and foreign productivity $\left(A_{H}, A_{F}\right)$, the home demand for domestic goods $\left(\omega_{H}\right)$, the home supply of money and government bonds $\left(M_{H}, B\right)$, the foreign labor-leisure choice $\left(\nu_{F}\right)$, the foreign appetite for US bonds $\left(\psi_{F}\right)$, and under a flexible exchange rate regime, to the foreign official demand for US bonds $\left(B_{F}^{G}\right)$. All shocks are assumed to follow AR(1) processes with an AR coefficient of 0.9 and a standard deviation of the error term of 0.01 . 
Table 1: Parametrization

\begin{tabular}{|c|c|c|}
\hline Parameter & & \\
\hline Discount factor & $\beta$ & 0.96 \\
\hline Consumption curvature & $\sigma$ & 2.00 \\
\hline Labor supply curvature & $\phi$ & 1.00 \\
\hline Bond holdings curvature & $\gamma$ & 3.00 \\
\hline Substitution domestic/foreign & $\eta$ & 4.00 \\
\hline Share of foreign traded & $1-\alpha$ & 0.25 \\
\hline Markup & $\mu$ & 1.20 \\
\hline \multicolumn{3}{|l|}{ Shocks } \\
\hline Persistence & $\rho$ & 0.90 \\
\hline Standard deviation & $s_{\epsilon}$ & 0.01 \\
\hline
\end{tabular}

\section{The results}

The model is linearized around a symmetric steady state and solved at the first order using Dynare. Our main interest is in comparing the impact of various disturbances on asset prices across regimes.

Let us try to understand the properties of the model by studying the impact of various shocks under a flexible exchange rate regime. Table 2 reports the impact effects on some key macroeconomic variables and Table 4 on the main financial variables.

Consider first a positive, domestic (US) productivity shock. Domestic output increases and its nominal price -given the stock of money- decreases. The increased supply of domestic output reduces also its relative price, i.e. the domestic terms of trade worsen. To the extent that the terms of trade deterioration is not so big as to make the foreign country the main beneficiary of the domestic productivity improvement (an event that would occur if the elasticity of substitution between domestic and foreign traded goods were very low) the home country will experience a current account improvement. Hence, domestic demand for assets increases both for the equity of the -more productive- home firms but also for internationally traded assets such as bonds and foreign equity. Bond and equity prices increase as do the domestic residents' holdings of the internationally traded bonds. Note that higher stocks prices for foreign firms obtain in spite of the fact that foreign output and dividends decrease ${ }^{3}$ because of the reduction in the stochastic discount factor for these dividends.

Consider now an unanticipated increase in home's supply of money. Domestic prices increase

\footnotetext{
${ }^{3}$ This is due to the fact that the income effect on foreign leisure from the favorable change in the foreign terms of trade dominates over the substitution effect.
} 
and the USD depreciates. What happens to the domestic terms of trade can be determined using a key result from the theory of transfers (Caves et al., 2006). The holders of domestic bonds suffer a capital loss as the real value of their bonds decreases and wealth is redistributed away from foreign towards domestic residents (due to the positive foreign position in domestic currency bonds). For the trade shares assumed, there is also a secondary loss for the transferor, that is, the foreign terms of trade deteriorate. The redistribution of wealth towards the US increases the US demand for assets. Equity and bond prices increase and the US experiences a current account improvement. As above, employment and output at home decrease (but consumption increases) while they increase in the foreign country due to the dominance of the wealth effects.

What about the effects of foreign shocks? Two shocks have been emphasized in the literature. The increase in the supply of labor in China (more precisely, the move from under-employment in agriculture into employment in manufacturing). And an increase in the foreign appetite for US safe assets. We model the former with an increase in the desire to work in the foreign country (a decrease in the dis-utility of labor $\nu_{F}$ ) and the latter with an increase in the utility of USD bonds abroad (an increase in $\psi$ ).

A decrease in $\nu_{F}$ leads to an increase in employment and output in the foreign country, a decrease in US inflation and to a depreciation of the USD. Nonetheless, the US terms of trade improve because of the large reduction in foreign prices. The foreign current account improves, with foreign bond holdings and equity prices increasing and the real interest rate decreasing.

Making US bonds more desirable in the foreign country has very similar effects to those described above. The only difference is that the USD now appreciates. Again interest rates decline, equity prices increase and the foreign country experiences a current account improvement. Consequently, both foreign shocks have the effects that have been discussed in the literature (see Dooley et al. 2004 for the former and Caballero et al., 2008, for the latter).

Let us now address the main question raised in this paper. Tables 3 and 5 are the analogues of Table 2 and 4 and describe the response of the economy under a perfectly -unilateral- fixed exchange rate regime. Are equity prices more responsive to shocks under a fixed than under a flexible exchange rate regime? The results -which are robust to variation in the parameters of the model- indicate that this is not the case.

As expected, for changes in the foreign private demand for safe assets, the peg acts as a perfect shock absorber. The government steps in and supplies the extra quantity demanded in order to prevent the change in the USD exchange rate. So such shocks have a bigger impact on equity prices under a flexible exchange rate system. Similarly, the peg eliminates the effects of some other shocks such as an increase in US government debt. It also mitigates the effect of an 
increase in the Chinese labor supply.

It has been argued (Dellas and Tavlas, 2010) that BWII, much alike to BWI, has allowed the US authorities to create large quantities of liquidity (because its effect on US inflation and interest rates is moderated by the use of the USD as international reserves), and that this liquidity has chased after assets, pushing up their prices. The main two forms of liquidity are US money and government bonds ${ }^{4}$. Even abstracting from the endogenous aspects of liquidity creation by the US policymakers (an issue beyond the scope of the current analysis) it is still interesting to ask how money and debt expansion affect equity prices in our model, whether the effects seem large (relative to the other shocks) and whether they differ across exchange rate systems. Consistent with the argument advanced by Dellas and Tavlas, 2010, we find that US monetary expansion has large and persistent effects on equity prices (with an elasticity of about one). But the extra contribution of the fixed regime, while positive, is albeit quite small. Public debt expansion also has quite large effects (about half of those associated with monetary expansion) but only under a flexible exchange rate system (the effect is null under a unilateral peg). All these findings, taken together, seem to indicate that asset price inflation in the US materialized in a fashion that was little shaped by the prevailing exchange rate regime with China.

\section{Possible Extensions}

The main extension carried out was to employ sticky instead of flexible prices (and also to consider an interest rate rule in place of the exogenous money supply rule used in the analysis above). We relied on a price adjustment costs specification a la Rotemberg, 1982. The results are reported in the appendix. It can be seen that making prices sticky makes little difference to the findings reported above.

Similarly, we tried to capture official Chinese impediments to private capital flows by imposing a tax on foreign holdings of US debt ${ }^{5}$ under both exchange rate regimes. This is the relevant experiment because having a tax only under a peg confounds the effects of capital account restrictions and the management of the exchange rate, which can be quite different operations. Again, the main results remained unaffected.

\footnotetext{
${ }^{4}$ It is worth mentioning that the debt of GSEs (such as Freddie Mac and Fannie Mae) was also perceived as a safe, liquid asset and proved a very popular investment with the Chinese government. Such debt expanded dramatically during the early part of the previous decade.

${ }^{5}$ Using capital controls instead make the solution to the problem non-linear and complicates the analysis considerably without offering any obvious compensating benefits.
} 


\section{Conclusions}

During the period leading to the recent financial crisis, a broad set of asset prices in the US increases significantly. At the same time, the US run large current account deficits, in particular against China, and a large share of these deficits was financed by the purchase of US safe assets (government and GSE bonds) by the Chinese monetary authorities. A possible explanation for the Chinese accumulation of safe, liquid US agents is China's desire to manage its USD/rimni exchange rate.

The objective of this paper is to assess the contribution of this unilateral peg to asset price inflation in the US. To this purpose we have used a simple portfolio balance model with flexible prices. While the model lacks realistic business cycle features and has not been calibrated to these two countries, we think that the resulting analysis carries useful insights into the role of alternative exchange rate systems for asset price behavior, both at the general level and at the specific US-China experience. Our main finding is that all the key factors that have been identified in the literature as important contributors to the US asset price inflation (the relocation of labor in China towards the traded sector, an increase in the LDCs appetite for safe, liquid US assets, monetary and debt expansion in the US) do indeed have the predicted effects. Nonetheless, the management of the USD/rimni rate does not seem to have played a significant role in the response of US asset prices to the various domestic and international disturbances.

A useful extension of the current paper would be to pursue a more quantitative route on the sources of asset price inflation as well as the contribution of the exchange rate regime by using a richer, properly calibrated model. It should be noted, though, that such a task faces considerable challenges because the Chinese economy is far away from its steady state and it is managed in a way that is not well captured by the neoclassical model (capital controls, under-employment, etc).

\section{References}

Caballero, R.J, E. Farhi, and P.O. Gourinchas, 2008, An Equilibrium Model of Global Imbalances and Low Interest Rates, American Economic Review, 98 (1), 358-393.

Caballero. R. J, and A. Krishnamurthy, 2009. "Global Imbalances and Financial Fragility," American Economic Review, 99(2), 584-88.

Caves, R., J. Frankel and R. Jones, 2006, World Trade and Payments: An Introduction, Pearson. 
Collard, F., H. Dellas, B. Diba and Alan Stockman, 2007, Goods Trade and International Equity Portfolios, NBER wp \# 13612.

Dellas, H., 2006, Monetary Policy in an Open Economy, European Economic Review, 50, (6) $1471-1486$.

Dellas, H. and G. Tavlas, 2010, "Global Liquidity and Asset Prices", mimeo.

Devereux, M. and A. Sutherland, 2010, "Country Portfolio Dynamics" Journal of Economic Dynamics and Control, 34, 1325-1342.

Dooley, M.P., D. Folkerts-Landau and P. Garber, 2004, The Revived Bretton Woods System: The Effects of Periphery Intervention and Reserve Management on Interest Rates and Exchange Rates in Center Countries, NBER WP No. 10332 .

Rotemberg, J., 1982, Monopolistic Price Adjustment and Aggregate Output," Review of Economic Studies, 49(4), 517-31. 
Table 2: Flexible Exchange Rates I

\begin{tabular}{lccccc}
\hline \hline & $X_{H}$ & $X_{F}$ & $\pi$ & $C A_{F}$ & $q$ \\
\hline$z_{A h}$ & 0.374 & -0.083 & -0.054 & -0.008 & 0.028 \\
$z_{B}$ & 0.614 & -0.614 & 0.086 & -0.101 & 0.122 \\
$z_{m h}$ & -0.340 & 0.340 & 0.053 & 0.047 & -0.068 \\
$z_{B F}^{G}$ & -0.878 & 0.878 & -0.122 & 0.144 & -0.175 \\
$z_{\nu f}$ & -0.755 & 2.211 & -0.113 & 0.097 & -0.208 \\
$z_{\psi f}$ & -0.285 & 0.285 & -0.040 & 0.047 & -0.057 \\
\hline \hline
\end{tabular}

Note: The shocks are to: home productivity, supply of bonds, money supply; foreign government holdings of bonds, labor supply and private demand for bonds. $\pi$ is CPI inflation and $\mathrm{q}$ is the terms of trade $\left(=e * p_{F} / p_{H}\right)$.

Table 3: Unilateral Peg I

\begin{tabular}{lcccccc}
\hline \hline & $X_{H}$ & $X_{F}$ & $\pi$ & $C A_{F}$ & $q$ & $B_{F}^{G}$ \\
\hline$z_{A h}$ & 0.444 & -0.153 & -0.044 & -0.020 & 0.042 & -0.025 \\
$z_{B}$ & 0.000 & 0.000 & 0.000 & 0.000 & 0.000 & -1.000 \\
$z_{m h}$ & -0.264 & 0.264 & 0.063 & 0.035 & -0.053 & 0.119 \\
$z_{\nu f}$ & -0.766 & 2.222 & -0.114 & 0.099 & -0.211 & 0.125 \\
$z_{\psi f}$ & 0.000 & 0.000 & 0.000 & 0.000 & 0.000 & -0.324 \\
\hline \hline
\end{tabular}

Note: The shocks are to: home productivity, supply of bonds, money supply; foreign labor supply. $\pi$ is CPI inflation and $\mathrm{q}$ is the terms of trade $\left(=e * p_{F} / p_{H}\right)$. 
Table 4: Flexible Exchange Rates II

\begin{tabular}{lccccccc}
\hline \hline & $Q_{H}$ & $Q_{F}$ & $R$ & $r$ & $e$ & $B_{H}$ & $B_{F}$ \\
\hline$z_{A h}$ & 0.088 & 0.050 & -0.001 & -0.006 & -0.027 & 0.008 & -0.008 \\
$z_{B}$ & 0.097 & -0.054 & 0.078 & 0.049 & 0.232 & 1.101 & -0.101 \\
$z_{m h}$ & 0.198 & 0.253 & -0.013 & -0.003 & -0.028 & 0.053 & -0.053 \\
$z_{B F}^{G}$ & 0.024 & 0.149 & -0.020 & -0.030 & -0.332 & -0.144 & -0.856 \\
$z_{\nu f}$ & 0.034 & 0.288 & -0.015 & -0.024 & 0.004 & -0.097 & 0.097 \\
$z_{\psi f}$ & 0.008 & 0.048 & -0.007 & -0.010 & -0.108 & -0.047 & 0.047 \\
\hline \hline
\end{tabular}

Note: The shocks are to: home productivity, supply of bonds, money supply; foreign government holdings of bonds, labor supply and private demand for bonds. $r$ is the ex ante home real interest rate.

Table 5: Unilateral Peg II

\begin{tabular}{lcccccccc}
\hline \hline & $Q_{H}$ & $Q_{F}$ & $R$ & $r$ & $e$ & $B_{H}$ & $B_{F}$ & $B_{F}^{G}$ \\
\hline$z_{A h}$ & 0.090 & 0.039 & -0.001 & -0.004 & 0.000 & 0.020 & 0.005 & -0.025 \\
$z_{B}$ & 0.000 & 0.000 & 0.100 & 0.000 & 0.000 & 1.000 & 1.000 & -1.000 \\
$z_{m h}$ & 0.210 & 0.246 & -0.016 & 0.006 & 0.000 & 0.065 & -0.184 & 0.119 \\
$z_{\nu f}$ & 0.042 & 0.293 & -0.018 & -0.011 & 0.000 & -0.099 & -0.027 & 0.125 \\
$z_{\psi f}$ & 0.000 & 0.000 & 0.000 & 0.000 & 0.000 & 0.000 & 0.324 & -0.324 \\
\hline \hline
\end{tabular}

Note: The shocks are to: home productivity, supply of bonds, money supply; foreign government holdings of bonds, labor supply and private demand for bonds. $r$ is the ex ante home real interest rate. 


\section{$5 \quad$ Appendix}

Sticky prices

We adopt Rotemberg's specification of price adjustment costs. In particular, we assume that intermediate goods firms face a cost - measured in terms of the final good-whenever they change their price. In particular, the cost takes the form

$$
\Omega_{H t}=(\chi / 2)\left(P_{H t} / P_{H t-1}-1\right)^{2} P_{t} Y_{H t}
$$

Note that we now have the following uses for the final good

$$
Y_{H t}=\Omega_{H t}+c_{H t}
$$

The optimal price chosen by the home intermediate firms in period $t$ is given by

$$
\begin{aligned}
(1-\theta) X_{H t}+ & \left(w_{H t} / A_{H t}\right)\left(X_{H t} / P_{H t}\right) \theta-\chi\left(P_{H t} / P_{H t-1}-1\right)\left(P_{t} Y_{H t} / P_{H t-1}\right. \\
& +\beta\left(\Lambda_{H t+1} / \Lambda_{H t}\right)\left(P_{H t+1} / P_{H t}-1\right)\left(P_{t+1} Y_{H t+1}\right)\left(P_{H t+1} / P_{H t}^{2}\right)
\end{aligned}
$$

Similar equations characterize the foreign economy.

Tables 6-7 give the response of the financial variables under a flexible and a fixed exchange rate regime when intermediate goods prices are sticky. 
Table 6: Flexible Exchange Rates, sticky prices

\begin{tabular}{lccccccc}
\hline \hline & $Q_{H}$ & $Q_{F}$ & $R$ & $r$ & $e$ & $B_{H}$ & $B_{F}$ \\
\hline$z_{A h}$ & 0.058 & 0.014 & 0.007 & 0.013 & -0.013 & 0.010 & -0.010 \\
$z_{B}$ & 0.095 & -0.024 & 0.079 & 0.048 & 0.224 & 1.125 & -0.125 \\
$z_{m h}$ & 0.240 & 0.296 & -0.027 & -0.030 & -0.046 & 0.037 & -0.037 \\
$z_{B F}^{G}$ & 0.005 & 0.116 & -0.019 & -0.022 & -0.322 & -0.199 & -0.801 \\
$z_{\nu f}$ & 0.056 & -0.209 & -0.027 & -0.043 & -0.043 & -0.081 & 0.081 \\
$z_{\psi f}$ & 0.002 & 0.038 & -0.006 & -0.007 & -0.104 & -0.064 & 0.064 \\
\hline
\end{tabular}

Note: The shocks are to: home productivity, supply of bonds, money supply; foreign government holdings of bonds, labor supply and private demand for bonds. $r$ is the ex ante home real interest rate.

Table 7: Unilateral Peg, sticky prices

\begin{tabular}{lcccccccc}
\hline \hline & $Q_{H}$ & $Q_{F}$ & $R$ & $r$ & $e$ & $B_{H}$ & $B_{F}$ & $B_{F}^{G}$ \\
\hline$z_{A h}$ & 0.067 & 0.013 & 0.009 & 0.014 & 0.000 & 0.018 & 0.045 & -0.063 \\
$z_{B}$ & 0.000 & 0.000 & 0.100 & 0.100 & 0.000 & 1.000 & 1.000 & -1.000 \\
$z_{m h}$ & 0.243 & 0.283 & -0.030 & -0.039 & 0.000 & 0.064 & -0.237 & 0.173 \\
$z_{\nu f}$ & 0.033 & -0.234 & -0.026 & -0.044 & 0.000 & -0.055 & 0.082 & -0.027 \\
$z_{\psi f}$ & 0.000 & 0.000 & 0.000 & 0.000 & 0.000 & 0.000 & 0.324 & -0.324 \\
\hline \hline
\end{tabular}

Note: The shocks are to: home productivity, supply of bonds, money supply; foreign labor supply and private demand for bonds. $r$ is the ex ante home real interest rate. 